\title{
Central fever: a challenging clinical entity in neurocritical care
}

\author{
Keshav Goyal, MD, DM'; Neha Garg, MD²; Parmod Bithal, MD³ \\ 'Department of Neuroanaesthesiology and Critical Care, Neurosciences Centre, All India Institute \\ of Medical Sciences, New Delhi, India \\ ${ }^{2}$ Institute of Liver and Biliary Science, Delhi, India \\ ${ }^{3}$ Department of Anesthesiology, King Fahd Medical City, Riyadh, Saudi Arabia
} \\ Review Article \\ Received: July 18, 2019 \\ Revised: December 12, 2019 \\ Accepted: December 13, 2019 \\ Corresponding Author: \\ Keshav Goyal, MD, DM \\ Department of Neuroanaesthesiology \\ and Critical Care, Neurosciences \\ Centre, All India Institute of Medical \\ Sciences, 710, New Delhi 110029, India \\ Tel: +91-11-26588700-4111 \\ E-mail: Keshavgoyalster@gmail.com}

Fever is probably the most frequent symptom observed in neurointensive care by healthcare providers. It is seen in almost $70 \%$ of neurocritically ill patients. Fever of central origin was first described in the journal Brain by Erickson in 1939. A significant number of patients develop this fever due to a noninfectious cause, but are often treated as having an infectious fever. Unjustified use of antibiotics adds to the increased cost of treatment and the emergence of resistant strains, contributing to additional morbidity. Since fever has a detrimental impact on the recovery of the acutely injured brain and contributes to an increased stay in the neurointensive care unit (NICU), timely and accurate diagnosis of the cause of fever in the NICU is imperative. Here, we try to understand the underlying mechanism, risk factors, clinical characteristics, diagnosis and management options of the central fever. We also make an attempt to differentiate two noninfectious causes of fever in the NICU: paroxysmal sympathetic hyperactivity and central fever.

Keywords: Humans; Fever; Brain; Intensive care units; Ant-bacterial agents

\section{INTRODUCTION}

Fever is probably the most frequent symptom observed in the neurointensive care unit (NICU) by healthcare providers. An oral temperature greater than $37.5^{\circ} \mathrm{C}$ is considered a fever [1,2]. Hyperpyrexia is usually a diagnosis of exclusion, with temperatures exceeding $41^{\circ} \mathrm{C}$ and nonresponsiveness to antipyretic treatment $[3,4]$. Fever is seen in almost $70 \%$ of neurocritically ill patients [5-10]. Fever of central origin was first described by in the journal Brain by Erickson [11] in 1939. A significant number of these patients have fever from noninfectious causes (47\% in Kilpatrick et al. [6] and 25\% in Commichau et al. [7]), but this is of- ten treated as infectious fever. Unjustified use of antibiotics adds to the increased cost of treatment and the emergence of resistant strains, contributing to additional morbidity. Since fever has a detrimental impact on the recovery of the acutely injured brain [12-15] and contributes to an increase in length of stay in NICU [8]; timely and accurate diagnosis of the cause of fever in the NICU is imperative.

Here, we try to understand the underlying mechanism, risk factors, clinical characteristics, diagnosis and management options of central fever (CF). We also make an attempt to differentiate two noninfectious causes of fever in NICU, paroxysmal sympathetic hyperactivity and $\mathrm{CF}$. 


\section{EPIDEMIOLOGY}

Overall in the intensive care unit (ICU), at least $50 \%$ of fever are reported to be due to noninfectious causes [16]. The incidence of noninfectious fever in the neurology ICU is $23 \%$ while in the neurosurgical ICU it is 47\% [6]. Of these, the highest rates of febrile episodes occur in patients with subarachnoid hemorrhage (SAH; $50 \%$ to $65 \%$ ), followed by traumatic brain injury (TBI; $4 \%$ to $40 \%)$ and intracerebral hemorrhage ( $\mathrm{ICH} ; 31 \%)$, with no cause of fever identified in $28 \%$ of patients, suggesting fever of central origin $[7,10,17,18]$. Hyperthermia is a frequent complication of acute ischemic stroke in $50 \%$ of these patients and carries a poor prognosis [19].

\section{PATHOPHYSIOLOGY}

An abnormal rise in temperature may be physiological, environmental, or even drug-related, rather than due to infection. The mechanism of CF in the NICU is not well defined but the literature suggests some probable mechanisms. Inflammatory markers causing fever may be triggered by extreme physiologic stress in acute neurologic injury $[20,21]$. Brain injury may also lead to the disruption of the mesencephalic-diencephalic mechanisms responsible for the inhibition of thermogenesis [22]. Monocytes and macrophages produce the cytokines interleukin 1 (IL-1), IL6 , and tumor necrosis factor $\alpha$ (TNF- $\alpha$ ), which act on the organum vasculosum of laminae terminalis. This in turn leads to the release of prostaglandin E2 (PGE2) via activation of the cyclooxygenase-2 (COX-2) enzyme. PGE2 acts on the preoptic area of the hypothalamus leading to an increase in the set point of the hypothalamus, thereby increasing the body temperature [23-34]. Systemic pyrogens, such as IL-1, appear to enter the brain at regions where there is an incomplete blood-brain barrier (circumventricular organs) and act on the preoptic area of the hypothalamus to induce fever [24,35-38]. Various neurological events that take place in febrile patients affect this pathway. Direct hemotoxic damage to thermoregulatory centers in the preoptic region, interference with tonic inhibitory inputs from lower midbrain that ordinarily suppresses thermogenesis, and stimulation of prostaglandin production leading to temperature set point elevation, have all been implicated in the causation of CF [39]. CF is speculated to result from damage to the hypothalamus, midbrain, or pons, and be enhanced by increased sympathetic activity, opening of the ventricles, damage to the frontal lobes, physical distortion, diffuse axonal injury (DAI), or toxic blood metabolites [39]. CF may also be due to the selective loss of warm-sensitive neurons, the osmotic changes detected by the organum vasculosum laminae ter- minalis, or from hormonal changes (progesterone, prostaglandin) modifying the firing rate of temperature-sensitive neurons in the medial preoptic nucleus [40].

Posttraumatic hyperthermia, also known as neurogenic fever, is another common cause of fever. Stimulation studies have suggested that the mechanism involves an imbalance between the hypothalamus and the various temperature regulating centers in the brainstem and spinal cord [41]. Won and Lin [42], in their study conducted on rabbits, found that inhibition of five hydroxytryptamine receptors in the anterior hypothalamus increased heat production and decreased heat loss, leading to hyperthermia. Suggested mechanisms for this effect include increased metabolic rate, increased carbon dioxide production, decreased cerebral blood flow, acidosis, brain edema exacerbation, excitotoxic neurotransmitter release, and blood-brain barrier breakdown. Disease-specific mechanisms are also described in Table 1.

\section{Subarachnoid hemorrhage}

SAH may cause impairment of hypothalamic thermoregulation due to the presence of clots in the suprasellar cistern. It may also lead to an intense activation of the sympathetic nervous system, leading to peripheral vasoconstriction and thus diminishing the heat-dissipating mechanisms [43].

\section{Intracerebral hemorrhage}

Intraventricular hemorrhage (IVH) is thought to elevate the temperature set point in the hypothalamus by direct damage to the thermoregulatory centers in the preoptic region, stimulation of prostaglandin production, or decreased inhibitory feedback from the lower midbrain which suppresses thermogenesis [39].

\section{Tumors}

It is hypothesized that a tumor, or its necrotic products, may lead to inflammation of leptomeninges, thus triggering fever [44].

\section{Traumatic brain injury}

While TBI can affect all seven pituitary hormones [45], growth hormone $(\mathrm{GH})$ deficiency is most frequently reported $[46,47]$. Patients with GH deficiency have a reduced sweating capacity which increases the risk of developing hyperthermia [48]. TBI-induced hypothalamic-pituitary damage may be due to direct injury to the hypothalamic-pituitary area, a secondary injury from hypoxia, or increased intracranial pressure [49]. CF in patients with TBI can also be caused by direct injury to the hypothalamus $[15,50]$. The development of CF is associated with inflammatory changes within the hypothalamus [51]. 
Table 1. Various neurological diseases and their relation with central fever

\begin{tabular}{|c|c|c|c|}
\hline Disease & Probable mechanisms & Risk factors & Effects on outcome \\
\hline \multirow[t]{2}{*}{ TBI } & 1. GH deficiency & 1. Diffuse axonal Injury & $\begin{array}{l}\text { 1. A negative association between early } \\
\text { peak fever greater than } 39^{\circ} \mathrm{C} \text { and hospital } \\
\text { mortality }\end{array}$ \\
\hline & $\begin{array}{l}\text { 2. Direct injury to the hypothalami } \\
\text { area or secondary injury from } \\
\text { increased intracranial pressure. }\end{array}$ & 2. Frontal lobe injuries & $\begin{array}{l}\text { 2. Possibility of antibiotic overuse, with the } \\
\text { associated risk of the emergence of } \\
\text { resistant microorganisms }\end{array}$ \\
\hline
\end{tabular}

3. Young age, low GCS on presentation, 3. Prolonged coma or unawareness, diabetes skull fracture, presence of blood in the insipidus and poor outcomes parenchyma/ventricles, and acute brain injury.

4. Location of the skull fracture in proximity to the hypothalamic region (for example, anterior fossa)

$\mathrm{ICH}$
1. Direct damage to thermoregulatory centres 1. ICH with intraventricular extension in the preoptic region, stimulation of prostaglandin production, and decreased inhibitory feedback from the lower midbrain which suppresses thermogenesis

2. Larger hematoma volumes

3. Basal ganglia and thalamic involvement

4. Third ventricular shift
1. High mortality and poor functional outcome at 3 months on modified Rankin Scale

2. Duration of fever was independently associated with poor outcome in those who survived past 72 hours.
SAH

Tumours

AIS
1. Impair hypothalamic thermoregulation D
due to presence of clots in suprasellar due to
cistern.

2. Intense activation of the sympathetic nervous system

Tumour or its necrotic products may lead More prone with tumours located in the Poor outcome to inflammation of leptomeninges, thus sella, diencephalon, and intraventricular triggering fever.

Hypothalamic dysfunction region

It is probable, larger the ischemia more the 1. May increase volume of the ischemic chances of $\mathrm{CF}$
1. Even a single episode of fever after SAH is associated with poorer outcomes even in best-grade patients.

2. $\uparrow$ Vasospasm associated with $\mathrm{CF}$

3. More severe functional disability and cognitive impairment among survivors

2. $\uparrow$ Mortality in stroke patients

$\mathrm{TBI}$, traumatic brain injury; GH, growth hormone; GCS, Glasgow Coma Scale; ICH, intracerebral hemorrhage; SAH, subarachnoid hemorrhage; IVH, intraventricular hemorrhage; $C$, central fever; AIS, acute ischemic stroke.

\section{Etiology}

CF can occur following any acute brain injury (Table 2) [38,5256].

\section{RISK FACTORS}

Various predisposing factors have been defined for the occurrence of CF in the NICU. Independent predictors of CF on multivariate analysis include blood transfusion, SAH, IVH, tumor, or onset of fever within 72 hours of hospital admission [57]. Intraventricular catheterization is a risk factor for unexplained fever, which suggests a role for ventricular hemorrhage in the pathogenesis of CF [7]. Risk factors among various acute neurological conditions are re- ported as follows (Table 1).

\section{Subarachnoid hemorrhage}

Disease severity, amount of blood in the subarachnoid space, and IVH are strong risk factors for the development of fever [7,58,59].

\section{Intracerebral hemorrhage}

$\mathrm{ICH}$ with intraventricular extension and larger hematoma volumes (86.7 $\pm 66.5 \mathrm{~mL} \mathrm{CF}$ vs. $33.7 \pm 54.4 \mathrm{~mL}$ in no fever) are associated with an increased probability of developing CF [18]. There were no significant differences related to the anatomical location of hematoma and presence of CF, but involvement of the basal ganglia and thalamus showed a trend towards an increased chance 
Table 2. Causes of central fever

Subarachnoid haemorrhage
Intraventricular haemorrhage
Intracerbral haemorrhage
Tumours: sella, diencephalon, and intraventricular region [52]
Traumatic brain injury
Ischemic stroke
Pontine haemorrhage
Tuberculous meningitis [38]
Following hemispherectomies [53]
Following hemidecortication [54]
Traumatic spine injury [55]
Basilar artery occlusion [56]

of CF [18]. Third ventricular shift in ICH patients is associated with fever within 72 hours of admission and high discharge mortality [59].

\section{Tumors}

CF is more frequently associated with tumors located in the sella, diencephalon, and intraventricular regions $[52,57]$.

\section{Traumatic brain injury}

Patients with DAI, as shown via imaging, and frontal lobe injuries were independently associated with the presence of CF $[60,61]$. Other risk factors were young age, low Glasgow Coma Scale on presentation, skull fracture, presence of blood in the parenchyma/ ventricles, and acute brain injury [62]. CF is more common in severely ill TBI patients with diffuse white matter damage, brain edema, hyperglycemia, leukocytosis, and hypotension [61]. Frontal lobe injury may serve as an indication of hypothalamic injury, given the nature of mechanical forces within the skull during injury and the proximity of the hypothalamus to the ventricles. Location of the skull fracture in proximity to the hypothalamic region (for example, the anterior fossa) may increase this risk [60].

\section{Ischemic stroke}

Magnetic spectroscopy indicates that the temperature of the ischemic zone is higher than in normal areas of the brain. Therefore, larger ischemic infarcts are likely to increase the chance of CF [63].

\section{Traumatic spine injury}

$\mathrm{CF}$ is also reported after traumatic spine injury, with a mean incidence of $8 \%$ [55]. Cervical and thoracic level injuries are more commonly associated with fever, as compared to lumbar injuries. Complete spine injuries have a higher incidence than incomplete injuries [55]. The etiology of fever following spine injury is not thoroughly understood.

\section{Age}

CF generally occurs in the younger population, as compared to infectious fever [57].

\section{Level of consciousness}

Depressed level of consciousness has also been identified as an independent predisposing factor for noninfectious fever, mainly attributed to immobilization and the increased atelectasis found in these patients [7].

\section{CLINICAL FEATURES OF CENTRAL FEVER}

This is a diagnosis of exclusion. CF occurs early, typically within 72 hours of admission after acute brain injury. All the cultures are negative and the chest radiograph is normal. Fever is disproportionately high and persistent. The temperature peak is higher when the fever starts earlier, and will be higher when compared to infectious fever [18]. There is generally less fever-free period and the cumulative fever load is high, accounting for a longer stay in the NICU. Generally, CF is continuous in nature without diurnal variations, plateau-like, and without spikes. Patients with CF have relative bradycardia with a notable absence of perspiration. Sustained fever is another factor in favor of CF [57]. Fever is also resistant to antipyretic medications [62,64-67].

Continuous fever, lasting longer than 6 hours for 2 or more consecutive days, has been considered persistent [57]. The combination of negative cultures; absence of infiltrate on chest radiographs; diagnosis of SAH, IVH, or tumor; and onset of fever within 72 hours of admission, predict CF with a probability of 0.90 [57]. In a study conducted by Thompson et al. [15], fever persisted for weeks to months in $4 \%$ to $37 \%$ of patients with TBI. Vasospasm with SAH is also predictive of CF [22].

The criteria for systemic inflammatory response syndrome and leukocytosis are similar to central and infectious fever. This underscores the difficulty in differentiating central and infectious fever prospectively in the critically ill population. The extreme physiologic stress provoked by acute neurologic injury can cause a rise in inflammatory markers and increased sympathetic response $[21,22]$. The percentage of neutrophils is higher in patients with infectious fever, suggesting that while leukocytosis may not be a reliable clinical variable to decide whether to use empirical antibiotics or discontinue antibiotics early, the presence of a left shift remains useful [57]. 
Extreme hyperpyrexia, defined as fever $\geq 41.1^{\circ} \mathrm{C}\left(106^{\circ} \mathrm{F}\right)$, is usually noninfectious. Examples include $\mathrm{CF}$, drug fever, malignant hyperthermia, transfusion reactions, adrenal insufficiency, thyroid storm, neuroleptic malignant syndrome, heat stroke, acalculous cholecystitis, mesenteric ischemia, acute pancreatitis, deep vein thrombosis, and pulmonary embolism [68,69]. A single fever spike of $102^{\circ} \mathrm{F}$ is classical for noninfectious disorders and is never due to infection. Fever associated with blood transfusions are usually transient, that is, they present as a single fever spike within $<1$ week $[68,70]$.

\section{TEMPERATURE PULSE RELATIONSHIP}

Relative bradycardia is a feature of CF. The following applies to adult patients with temperatures $>102^{\circ} \mathrm{F}$ and when pulse is taken simultaneously with temperature. Normally, the pulse rises in concert with the temperature, (e.g., for every degree Fahrenheit temperature is increased, the pulse should rise 10 beats $/ \mathrm{min}$ ). If the pulse rate is lower than predicted from a given temperature $\left(>102^{\circ} \mathrm{F}\right)$, then relative bradycardia is present, unless the patient is on a beta-blocker, verapamil or diltiazem, or has a pacemaker-induced rhythm or heart block. In absence of these exclusion criteria, relative bradycardia in neurosurgical ICU patients with fever strongly suggests a central or drug fever (Table 3) [71].

\section{Diagnosis}

A high index of suspicion is needed for the diagnosis of CF. Diagnosis of $\mathrm{CF}$ is a diagnosis of exclusion in predisposed patients with neurological injury. The practice guidelines from the task force of the Society for Critical Care Medicine suggest a "careful clinical assessment" and "cost-conscious approach" for obtaining a diagnosis through laboratory and radiological tests [72]. The clinical signs of pneumonia, bacteremia, sinusitis, urinary tract infection, catheter site infection, meningitis, or ventriculitis should be investigated. A chest radiograph, culture of blood, urine and trachea are the baseline tests done in all cases. Any long-standing venous line or catheter should also be removed.

Certain biomarkers have been developed to differentiate infec-

Table 3. Temperature pulse relationship

\begin{tabular}{ccc}
\hline Temperature $\left({ }^{\circ} \mathrm{F}\right)$ Appropriate pulse response $(/ \mathrm{min})$ & Relative bradycardia \\
\hline 106 & 150 & $<140$ \\
105 & 140 & $<130$ \\
104 & 130 & $<120$ \\
103 & 120 & $<110$ \\
102 & 110 & $<100$ \\
\hline
\end{tabular}

tious from noninfectious causes, including serum procalcitonin (PCT) assays, endotoxin detection systems, triggering receptor expressed on myeloid cells-S (TREM-1), C-reactive protein, TNF- $\alpha$, and IL-6. PCT of $0.5 \mathrm{ng} / \mathrm{mL}$ or greater was useful in differentiating infectious fever from $\mathrm{CF}$ in $\mathrm{SAH}$ and $\mathrm{ICH}$ patients [73]. This test is shown to have high specificity and a reasonably high negative predictive value. A decision tree has been suggested by Hocker et al. [57], but no specific diagnostic paradigm has been suggested for universal usage.

\section{DIFFERENTIAL DIAGNOSIS}

Some common differential diagnoses are important to be distinguished before making a diagnosis of $\mathrm{CF}$, since it a diagnosis of exclusion. Nonresponse to antibiotics in CF may lead to misdiagnosis of antibiotic failure or resistance in CF (Table 4).

\section{Bacteremia}

Bacteremia should be investigated by sending at least three blood cultures within 24 hours of suspected infection. Each culture should be sent from a separate venepuncture site or intravascular device. Intravascular catheters should be suspected as an infection risk in young nonimmune compromised patients with abrupt onset of septicemia. These patients may have inflammation at the site of insertion that can provide a clue to the diagnosis, though this is absent in $60 \%$ of patients. Difficulty in drawing a sample from the line may be another indicator of intravenous catheter-related infection.

\section{Ventilator-associated pneumonia}

Ventilator-associated pneumonia is the second most common cause of infectious fever in any ICU. It is distinguished by a culture of respiratory secretion which can be obtained by various techniques, including expectoration, nasopharyngeal washing, saline induction, deep tracheal suctioning, bronchoscopic specimen/ brush samples, aspiration, and bronchoscopic or nonbronchoscopic lavage (mini-BAL). Chest radiography for abscess, atelectasis, effusion, and consolidation should also be done.

\section{Urinary tract infection}

Urinary tract infection is the next leading cause of fever. Diagnosis is excluded by sending urine for direct microscopic examination, staining, and culture.

\section{Diarrhea}

Diarrhea is another important cause of fever in the ICU. It should be suspected in any patient with diarrhea and who has been given 
Table 4. Differential diagnosis of fever in neurointensive care unit

\begin{tabular}{l} 
Infectious causes \\
Ventilator-associated pneumonia \\
Sinusitis \\
Meningitis \\
Encephalitis \\
Catheter-related sepsis \\
Sepsis \\
Clostridium difficile diarrhea \\
Abdominal sepsis \\
Complicated wound infections \\
Urinary tract infection \\
Acute respiratory distress syndrome, both late and fibro-proliferative \\
stage \\
Systemic inflammatory response syndrome \\
Noninfectious causes \\
Alcohol/drug withdrawal \\
Postoperative fever (48 hours postoperative) \\
Post-transfusion fever \\
Drug fever \\
Connective tissue disease \\
Myocardial infarction \\
Pancreatitis \\
Acalculous cholecystitis \\
Ischemic bowel (without primary peritonitis) \\
Gastrointestinal bleed \\
Aspiration pneumonitis \\
Fat emboli \\
Gout/pseudo gout \\
Transplant rejection \\
Hematoma \\
Cirrhosis \\
Decubitus ulcer \\
Phlebitis/thrombophlebitis \\
Intravenous contrast reaction \\
Neoplastic fever \\
\hline a
\end{tabular}

antibiotic treatment or chemotherapy in the past 60 days. The most common organism implicated is Clostridium difficile $[74,75]$. It can be excluded by enzyme immunosorbent assay (EIA) for detecting toxins $\mathrm{A}$ and $\mathrm{B}$, or by culture (though it is more time consuming).

\section{Sinusitis}

Sinusitis is an uncommon cause of fever in the ICU, but may have a grave impact on patient outcomes. Risk factors include obstruction of the ostia draining the sinuses, nasal intubation of trachea, or the passage of a nasogastric tube. Though occult, it can spread to the brain, lungs, and blood, leading to serious consequences [76]. It can be ruled out by a radiograph, ultrasound, magnetic resonance imaging or computed tomography scan transnasal puncture.

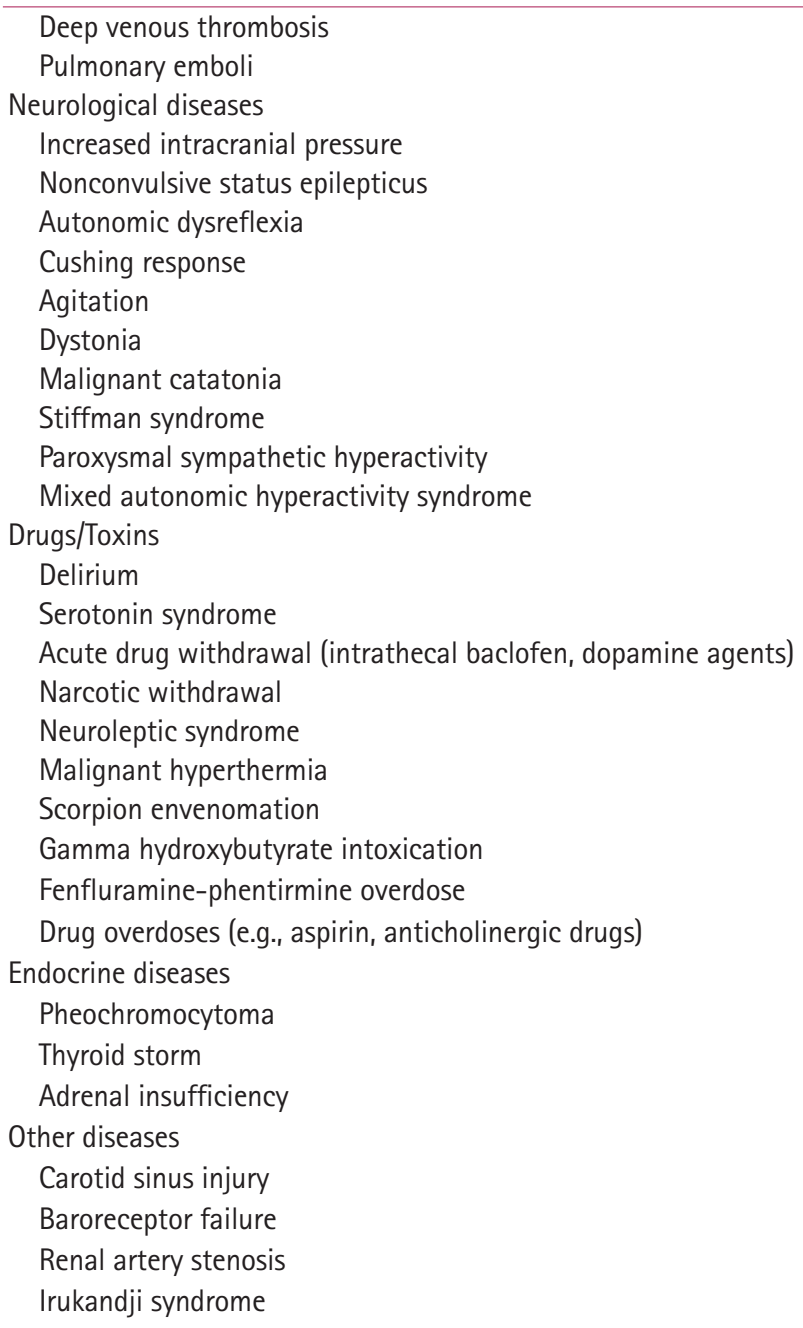

\section{Surgical site infection}

Surgical site infection accounts for 3\% of fever in the ICU, which can easily be diagnosed by local inspection and cultures from the wound site $[77,78]$. Abscess in the lung, abdomen or any other region may also be a cause of fever.

\section{Drug fever}

Drug fever is caused by some commonly used drugs in the NICU, such as phenytoin, salicylates, barbiturates, methyldopa, furosemide, penicillin, cephalosporin, sulfonamide, amphotericin B, rarely corticosteroids, clindamycin, tetracycline, macrolide. Onset of fever is usually within 1 to 2 weeks of drug initiation, and it can easily be diagnosed by stopping the drug. Suspicion of drug fever can also arise from relative bradycardia and the patient being inappropriately well for the degree of fever. Fever usually disappears within 3 days of stopping drugs or antibiotics in such cases 
Table 5. Paroxysmal sympathetic hyperactivity vs. central fever

\begin{tabular}{|c|c|c|}
\hline Feature & PSH & $\mathrm{CF}$ \\
\hline Onset & $\begin{array}{l}\text { Usually after a week of } A B I \text { and may last up to } 1 \text { year. } \\
\text { Generally seen after cessation of ICU sedation }\end{array}$ & Occurs within 72 hours of $A B I$ \\
\hline Associated signs and symptoms & Tachycardia, hypertension, tachypnoea, dystonia, diaphoresis & No such association \\
\hline Fever & $\begin{array}{l}\text { At least one episode per day for } 3 \text { consecutive days ( } 2-3 \\
\text { cycles/day) }\end{array}$ & $\begin{array}{l}\text { Unusually high fever remains for most of the time } \\
\text { (plateau-like with no diurnal variation) }\end{array}$ \\
\hline Trigger & Essential diagnostic criteria (mostly nonnoxious stimuli) & No such trigger defined \\
\hline Mechanism & Excitatory-inhibitory model: most commonly accepted & $\begin{array}{l}\text { Inflammatory cytokines increase the set point of } \\
\text { hypothalamus }\end{array}$ \\
\hline Leukocytosis & Generally absent & Present \\
\hline Heart rate & Tachycardia & Relative bradycardia \\
\hline Sweating & Generally present & Absent \\
\hline Posturing/Dystonia & Generally present (one of the diagnostic criteria) & Absent \\
\hline Pupil size & Usually increased & Normal \\
\hline Paroxysmal nature & Yes & No \\
\hline Most common pathology & $\mathrm{TBI}$ & $\mathrm{SAH}$ \\
\hline Diagnostic criteria & $\begin{array}{l}\text { Defined by multidisciplinary international committee } \\
\text { (diagnostic likelihood tool) }\end{array}$ & No such diagnostic criteria \\
\hline Core clinical features & Six core sympathetic and motor clinical features & No such clinical features \\
\hline
\end{tabular}

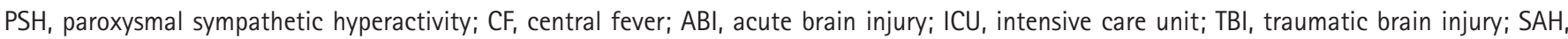
subarachnoid hemorrhage.

$[71,79]$.

Other differential diagnoses are listed in Table 4.

\section{PAROXYSMAL SYMPATHETIC HYPERACTIVITY VS. CENTRAL FEVER}

Both are diagnoses of exclusion in patients with neurological injuries during their stay in neurocritical care. They both occur in the NICU in acute brain-injury patients. Differentiating one from the other is very crucial in proper care and appropriate management, and thus ultimately affects patient outcomes. Differentiating features are listed in Table 5 .

\section{Impact on outcome}

Fever predisposes the brain to harmful effects by disrupting the blood-brain barrier, an increasing excitatory amino acid release, and increasing the production of free radicals [80]. There is an exacerbation of neuronal injury in fever. The permeability of the blood-brain barrier is related to body temperature and higher temperatures increase the extravasation of proteins $[81,82]$. There is a lack of literature for a definitive association between the duration of fever and increased mortality. Studies conducted by Circiumaru et al. [83] and Peres Bota et al. [84] found that fever lasting longer than 5 days was associated with increased mortality. These results are in contrast to a study conducted by Schulman et al.
[85], who found increased patient mortality when fever was aggressively controlled, although it should be noted that these were nonneurological trauma patients. Fever is also found to increase the length of ICU stay $[8,9]$.

The brain injury patient is at risk of secondary injury from fever, as for every $1^{\circ} \mathrm{C}$ rise in body temperature there is a $13 \%$ increase in the metabolic rate [86]. Increased body temperature causes permanent neuronal damage and worsens prognosis in animal models of ischemic brain injury [40,87-91]. Fever is also known to increase delirium and agitation $[92,93]$. However, fever is not found to increase intracranial pressure [94]. Fever also increases cardiac output, oxygen consumption, and heart rate [95]. This increased demand on the heart is poorly compensated in patients with previously compromised cardiac function and in sepsis [96]. Fever has also been associated with increased multiorgan dysfunction and mortality [97]. Higher temperature is further associated with cell protein denaturation, susceptibility to acid-base and electrolyte disturbances, and impaired oxygen release [98].

\section{Subarachnoid hemorrhage}

Even a single episode of fever after SAH is associated with poorer outcomes, even in good-grade patients [99]. Vasospasm in SAH patients is associated with $\mathrm{CF}$, independent of hemorrhage severity or the presence of infection $[7,12,22,57,100-102]$. Treatment-refractory fever during the first 10 days after $\mathrm{SAH}$ is associ- 
ated with increased mortality, more severe functional disability, and cognitive impairment among survivors [58]. Cumulative fever burden, defined as the sum of time with temperatures $>38.3^{\circ} \mathrm{C}$ in the first 13 days, is associated with worse outcomes, including incomplete recovery in good-grade $\mathrm{SAH}$ patients and potentially late recovery in poor-grade patients [102].

\section{Intracerebral hemorrhage}

The presence of CF leads to poor outcomes and is an independent risk factor for mortality in ICH patients [18]. This results in high mortality and poor functional outcomes at 3 months on the modified Rankin Scale. In one study, the presence of CF led to unfavorable outcomes in $100 \%$ cases at 90 days postictus, while the absence of fever was associated with unfavorable outcomes in only $46.9 \%$ of patients [18]. In a retrospective study of 251 patients with spontaneous $\mathrm{ICH}$, the duration of fever was independently associated with poor outcomes in those who survived past 72 hours [14].

\section{Acute ischemic stroke}

Pyrexia in experimental animals may increase the volume of the ischemic zone $[40,84-87]$. Also, fever greater than $39^{\circ} \mathrm{C}$ increases mortality in stroke patients [103].

\section{Traumatic brain injury}

In a cohort of more than 100,000 patients, a negative association was observed between early peak fever greater than $39^{\circ} \mathrm{C}$ and hospital mortality in patients with TBI [103]. Further, this correlation was not seen in patients with central nervous system infection. Because CF starts earlier and lasts longer than infectious fever, there is a high risk of antibiotic overuse and the associated risk of the emergence of resistant microorganisms [57]. CF may be associated with prolonged coma or unawareness, diabetes insipidus, and overall poor outcomes $[50,64,65,67,104]$.

\section{TREATMENT}

Although many treatment regimens have been suggested, none have been identified as superior to others in the treatment of fever $[65,105]$. However, controlling fever is an important part of management in $\mathrm{CF}$, owing to its detrimental effects on the brain. Pharmacologic methods include acetaminophen, acetylsalicylic acid, and other nonsteroidal antiinflammatory medications and corticosteroids [106,107].

Other methods to decrease temperature include rotary fans, sponging, and surface cooling devices. However, these have had limited efficacy and are uncomfortable for the patient. Surface cooling devices have also been reported to increase the incidence of shivering, increase oxygen consumption and even cause thermal burns $[107,108]$. Hypothermia blankets can lead to large temperature fluctuations $[109,110]$. Air blankets have been increasingly used and are found to have better efficacy and produce better patient comfort [110]. Some authors have suggested the use of sand body-conformed wraps, intravascular cooling devices, head-only cooling caps, or inhaled perfluorocarbon cooling systems [111].

Several studies have tried intravenous infusion of cold saline, showing promising results and no increase in complications [112]. A few studies have tried local (brain) cooling. This may prevent the side effects of global hypothermia, such as impaired coagulation, arrhythmias and deep vein thrombosis [113-116]. However, no large multicentre trial is available, leading to no definitive conclusions on the use of selective brain cooling.

IL-1 antagonists have been shown to produce significant improvements in rat models of TBI [117], although no human trials have been conducted. However, it has been shown that even a small temperature decrease in febrile patients can improve neurologic outcomes [118].

\section{Morphine}

Remission of CF is reported with morphine post-TBI [119].

\section{Chlorpromazine}

Sometimes, when traditional management fails, chlorpromazine has been tried with variable success. Chlorpromazine produces antipyretic actions because of its ability to render the patient thermolabile and its effect on thermoregulation [120,121]. Hyperpyrexia following hemispherectomy has been reported to respond to chlorpromazine [121].

\section{Baclofen}

Baclofen successfully abolished prolonged central hyperthermia in a patient with basilar artery occlusion leading to brain stem infarction [56].

\section{Bromocriptine}

There are anecdotal case reports of the successful use of bromocriptine for treatment of $\mathrm{CF}[122,123]$.

\section{Growth hormone therapy}

Successful treatment of CF by GH therapy has been reported, with the mechanism related to the improvement of sweat production [124]. 


\section{FUTURE DIRECTIONS}

There are no guidelines or directions to help differentiate CF from other noninfectious causes of fever in the NICU. The literature is sparse and unclear. The diagnostic criteria are not well defined and not standardized. Treatment modalities for this clinical entity have been symptomatic only and mostly rely on over the counter drugs. No standard therapy has been defined in the literature. Multicentre large studies are required to better define CF, understand its pathophysiology, and guide standard management protocols in neurocritical care settings.

\section{CONCLUSION}

$\mathrm{CF}$ is an important diagnosis in neurocritical care. It not only prevents unnecessary antibiotic use, but its early recognition would also help improve patient management and prevent delayed discharge from the hospital. The current key to diagnosis in a predisposed patient is a high index of suspicion, along with thorough clinical examination, radiological, microbiological, and biochemical tests. Immediate attainment of normothermia is the current recommendation, as fever worsens the brain insult. Treatment includes various pharmacological agents and surface cooling methods to decrease body temperature. Studies are lacking on the best methods for diagnosis, treatment, and prevention of CF. Thus, more human trials are needed in this field to make any definitive recommendations.

\section{ARTICLE INFORMATION}

\section{Conflict of interest}

No potential conflict of interest relevant to this article.

\section{ORCID}

Keshav Goyal, https://orcid.org/0000-0001-9139-0689

Neha Garg, https://orcid.org/0000-0003-4817-9807

Parmod Bithal, https://orcid.org/0000-0001-5348-2814

\section{Author contributions}

Conceptualization: KG, NG, and PB. Data curation \& Formal analysis: KG, NG, and PB. Visualization \& Writing-original draft: KG and PB. Writing-review editing: KG and NG.

\section{REFERENCES}

1. Axelrod YK, Diringer MN. Temperature management in acute neurologic disorders. Neurol Clin 2008;26:585-603.
2. Laupland KB. Fever in the critically ill medical patient. Crit Care Med 2009;37(7 Suppl):S273-8.

3. Grunau BE, Wiens MO, Brubacher JR. Dantrolene in the treatment of MDMA-related hyperpyrexia: a systematic review. CJEM 2010;12:435-42.

4. Sharma HS. Neurobiology of hyperthermia. Amsterdam: Elsevier; 2007:175-7. 485.

5. Albrecht RF 2nd, Wass CT, Lanier WL. Occurrence of potentially detrimental temperature alterations in hospitalized patients at risk for brain injury. Mayo Clin Proc 1998;73:629-35.

6. Kilpatrick MM, Lowry DW, Firlik AD, Yonas H, Marion DW. Hyperthermia in the neurosurgical intensive care unit. Neurosurgery 2000;47:850-6.

7. Commichau C, Scarmeas N, Mayer SA. Risk factors for fever in the neurologic intensive care unit. Neurology 2003;60:837-41.

8. Diringer MN, Reaven NL, Funk SE, Uman GC. Elevated body temperature independently contributes to increased length of stay in neurologic intensive care unit patients. Crit Care Med 2004;32:1489-95.

9. Stocchetti N, Rossi S, Zanier ER, Colombo A, Beretta L, Citerio G. Pyrexia in head-injured patients admitted to intensive care. Intensive Care Med 2002;28:1555-62.

10. Laws C, Jallo J. Fever and infection in the neurosurgical intensive care unit.JHNJ 2010;5:5.

11. Erickson TC. Neurogenic hyperthermia: a clinical syndrome and its treatment. Brain 1939;62:172-90.

12. Oliveira-Filho J, Ezzeddine MA, Segal AZ, Buonanno FS, Chang Y, Ogilvy CS, et al. Fever in subarachnoid hemorrhage: relationship to vasospasm and outcome. Neurology 2001; 56:1299-304.

13. Rossi S, Zanier ER, Mauri I, Columbo A, Stocchetti N. Brain temperature, body core temperature, and intracranial pressure in acute cerebral damage. J Neurol Neurosurg Psychiatry 2001;71:448-54.

14. Schwarz S, Häfner K, Aschoff A, Schwab S. Incidence and prognostic significance of fever following intracerebral hemorrhage. Neurology 2000;54:354-61.

15. Thompson HJ, Tkacs NC, Saatman KE, Raghupathi R, McIntosh TK. Hyperthermia following traumatic brain injury: a critical evaluation. Neurobiol Dis 2003;12:163-73.

16. Dimopoulos G, Falagas ME. Approach to the febrile patient in the ICU. Infect Dis Clin North Am 2009;23:471-84.

17. Otawara Y, Ogasawara K, Kubo Y, Tomitsuka N, Ogawa A, Suzuki $\mathrm{M}$. Brain and systemic temperature in patients with severe subarachnoid hemorrhage. Surg Neurol 2003;60:159-64.

18. Honig A, Michael S, Eliahou R, Leker RR. Central fever in patients with spontaneous intracerebral hemorrhage: predicting 
factors and impact on outcome. BMC Neurol 2015;15:6.

19. Zawadzka M, Szmuda M, Mazurkiewicz-Bełdzińska M. Thermoregulation disorders of central origin: how to diagnose and treat. Anaesthesiol Intensive Ther 2017;49:227-34.

20. Ntaios G, Dziedzic T, Michel P, Papavasileiou V, Petersson J, Staykov D, et al. European Stroke Organisation (ESO) guidelines for the management of temperature in patients with acute ischemic stroke. Int J Stroke 2015;10:941-9.

21. Tam AK, Ilodigwe D, Mocco J, Mayer S, Kassell N, Ruefenacht $\mathrm{D}$, et al. Impact of systemic inflammatory response syndrome on vasospasm, cerebral infarction, and outcome after subarachnoid hemorrhage: exploratory analysis of CONSCIOUS-1 database. Neurocrit Care 2010;13:182-9.

22. Rabinstein AA, Sandhu K. Non-infectious fever in the neurological intensive care unit: incidence, causes and predictors. J Neurol Neurosurg Psychiatry 2007;78:1278-80.

23. Mackowiak PA. Concepts of fever. Arch Intern Med 1998; 158:1870-81.

24. Saper CB, Breder CD. The neurologic basis of fever. N Engl J Med 1994;330:1880-6.

25. Dinarello CA, Cannon JG, Mier JW, Bernheim HA, LoPreste G, Lynn DL, et al. Multiple biological activities of human recombinant interleukin 1. J Clin Invest 1986;77:1734-9.

26. Dinarello CA. Interleukin-1 and the pathogenesis of the acutephase response. N Engl J Med 1984;311:1413-8.

27. Fontana A, Weber E, Dayer JM. Synthesis of interleukin 1/endogenous pyrogen in the brain of endotoxin-treated mice: a step in fever induction? J Immunol 1984;133:1696-8.

28. Gourine AV, Rudolph K, Tesfaigzi J, Kluger MJ. Role of hypothalamic interleukin-1beta in fever induced by cecal ligation and puncture in rats. Am J Physiol 1998;275:R754-61.

29. Kluger MJ, Kozak W, Leon LR, Conn CA. The use of knockout mice to understand the role of cytokines in fever. Clin Exp Pharmacol Physiol 1998;25:141-4.

30. Klir JJ, McClellan JL, Kluger MJ. Interleukin-1 beta causes the increase in anterior hypothalamic interleukin-6 during LPS-induced fever in rats. Am J Physiol 1994;266(6 Pt 2):R1845-8.

31. Klir JJ, Roth J, Szelényi Z, McClellan JL, Kluger MJ. Role of hypothalamic interleukin-6 and tumor necrosis factor-alpha in LPS fever in rat. Am J Physiol 1993;265(3 Pt 2):R512-7.

32. Dinarello CA, Cannon JG, Mancilla J, Bishai I, Lees J, Coceani F. Interleukin- 6 as an endogenous pyrogen: induction of prostaglandin E2 in brain but not in peripheral blood mononuclear cells. Brain Res 1991;562:199-206.

33. Dinarello CA, Wolff SM. The role of interleukin-1 in disease. $\mathrm{N}$ Engl J Med 1993;328:106-13.

34. Leon LR, White AA, Kluger MJ. Role of IL-6 and TNF in ther- moregulation and survival during sepsis in mice. Am J Physiol 1998;275:R269-77.

35. Ganong WF. Central regulation of visceral function. In: Ganong WF. ed. Review of medical physiology. 17th ed. Norwalk: Appleton \& Lange; 1995:210-32.

36. Kupfermann I. Hypothalamus and limbic system: motivation. In: Kandel ER, Schwartz JH, Jessell TM. eds. Principles of neural science. 3rd ed. New York: Elsevier; 1991:750-60.

37. Brazis PW, Masden JC, Biller J. Localization in clinical neurology. 3rd ed. Boston: Little Brown; 1996:381-400.

38. Alshahrani AM, Al-Said YA, Mamoun IA, Streletz LJ. Central fever due to hypothalamic lesion in a patient with tuberculous meningitis. Neurosciences (Riyadh) 2002;7:301-3.

39. Shibata M. Hyperthermia in brain hemorrhage. Med Hypotheses 1998;50:185-90.

40. Rango M, Arighi A, Airaghi L, Bresolin N. Central hyperthermia, brain hyperthermia and low hypothalamus temperature. Clin Auton Res 2012;22:299-301.

41. Boulant JA. Role of the preoptic-anterior hypothalamus in thermoregulation and fever. Clin Infect Dis 2000;31 Suppl 5: S157-61.

42. Won SJ, Lin MT. 5-Hydroxytryptamine receptors in the hypothalamus mediate thermoregulatory responses in rabbits. Naunyn Schmiedebergs Arch Pharmacol 1988;338:256-61.

43. Mayer SA, Lin J, Homma S, Solomon RA, Lennihan L, Sherman D, et al. Myocardial injury and left ventricular performance after subarachnoid hemorrhage. Stroke 1999;30:780-6.

44. Soffer D. Brain tumors simulating purulent meningitis. Eur Neurol 1976;14:192-7.

45. Tanriverdi F, Senyurek H, Unluhizarci K, Selcuklu A, Casanueva FF, Kelestimur F. High risk of hypopituitarism after traumatic brain injury: a prospective investigation of anterior pituitary function in the acute phase and 12 months after trauma.J Clin Endocrinol Metab 2006;91:2105-11.

46. Lindsay R, Feldkamp M, Harris D, Robertson J, Rallison M. Utah Growth Study: growth standards and the prevalence of growth hormone deficiency. J Pediatr 1994;125:29-35.

47. Kokshoorn NE, Wassenaar MJ, Biermasz NR, Roelfsema F, Smit JW, Romijn JA, et al. Hypopituitarism following traumatic brain injury: prevalence is affected by the use of different $d y$ namic tests and different normal values. Eur J Endocrinol 2010;162:11-8.

48. Juul A, Behrenscheer A, Tims T, Nielsen B, Halkjaer-Kristensen J, Skakkebaek NE. Impaired thermoregulation in adults with growth hormone deficiency during heat exposure and exercise. Clin Endocrinol (Oxf) 1993;38:237-44.

49. Agha A, Thompson CJ. Anterior pituitary dysfunction follow- 
ing traumatic brain injury (TBI). Clin Endocrinol (Oxf) 2006;64:481-8.

50. Crompton MR. Hypothalamic lesions following closed head injury. Brain 1971;94:165-72.

51. Thompson HJ, Hoover RC, Tkacs NC, Saatman KE, McIntosh TK. Development of posttraumatic hyperthermia after traumatic brain injury in rats is associated with increased periventricular inflammation. J Cereb Blood Flow Metab 2005; 25:163-76.

52. Clar HE. Clinical and morphological studies of pituitary and diencephalic space-occupying lesions before and after operation, with special reference to temperature regulation. Acta Neurochir (Wien) 1979;50:153-99.

53. De Almeida AN, Marino RJr. The early years of hemispherectomy. Pediatr Neurosurg 2005;41:137-40.

54. Kossoff EH, Vining EP, Pyzik PL, Kriegler S, Min KS, Carson BS, et al. The postoperative course and management of 106 hemidecortications. Pediatr Neurosurg 2002;37:298-303.

55. Savage KE, Oleson CV, Schroeder GD, Sidhu GS, Vaccaro AR. Neurogenic fever after acute traumatic spinal cord injury: a qualitative systematic review. Global Spine J 2016;6:607-14.

56. Huang YS, Hsiao MC, Lee M, Huang YC, Lee JD. Baclofen successfully abolished prolonged central hyperthermia in a patient with basilar artery occlusion. Acta Neurol Taiwan 2009; 18:118-22.

57. Hocker SE, Tian L, Li G, Steckelberg JM, Mandrekar JN, Rabinstein AA. Indicators of central fever in the neurologic intensive care unit. JAMA Neurol 2013;70:1499-504.

58. Fernandez A, Schmidt JM, Claassen J, Pavlicova M, Huddleston D, Kreiter KT, et al. Fever after subarachnoid hemorrhage: risk factors and impact on outcome. Neurology 2007; 68:1013-9.

59. Deogaonkar A, de Georgia M, Bae C, Abou-Chebl A, Andrefsky J. Fever is associated with third ventricular shift after intracerebral hemorrhage: pathophysiologic implications. Neurol India 2005;53:202-7.

60. Thompson HJ, Pinto-Martin J, Bullock MR. Neurogenic fever after traumatic brain injury: an epidemiological study. J Neurol Neurosurg Psychiatry 2003;74:614-9.

61. Young AB, Ott LG, Beard D, Dempsey RJ, Tibbs PA, McClain CJ. The acute-phase response of the brain-injured patient. J Neurosurg 1988;69:375-80.

62. Childers MK, Rupright J, Smith DW. Post-traumatic hyperthermia in acute brain injury rehabilitation. Brain Inj 1994; 8:335-43.

63. Karaszewski B, Wardlaw JM, Marshall I, Cvoro V, Wartolowska $\mathrm{K}$, Haga K, et al. Measurement of brain temperature with mag- netic resonance spectroscopy in acute ischemic stroke. Ann Neurol 2006;60:438-46.

64. Sazbon L, Groswasser Z. Outcome in 134 patients with prolonged posttraumatic unawareness: part 1: parameters determining late recovery of consciousness. J Neurosurg 1990; 72:75-80.

65. Cunha BA, Tu RP. Fever in the neurosurgical patient. Heart Lung 1988;17(6 Pt 1):608-11.

66. Segatore M. Fever after traumatic brain injury. J Neurosci Nurs 1992;24:104-9.

67. Powers JH, Scheld WM. Fever in neurologic diseases. Infect Dis Clin North Am 1996;10:45-66.

68. Cunha BA. Fever in the critical care unit. Crit Care Clin 1998; 14:1-14.

69. Cunha BA. The clinical significance of fever patterns. Infect Dis Clin North Am 1996;10:33-44.

70. Cunha BA. Clinical approach to fever in critical care. In: Cunha BA. ed. Infectious diseases in critical care medicine. 3rd ed. New York: Informa; 2010:1-18.

71. Cunha BA. Clinical approach to fever in the neurosurgical intensive care unit: focus on drug fever. Surg Neurol Int 2013; 4(Suppl 5):S318-22.

72. O’Grady NP, Barie PS, Bartlett JG, Bleck T, Garvey G, Jacobi J, et al. Practice guidelines for evaluating new fever in critically ill adult patients. Task Force of the Society of Critical Care Medicine and the Infectious Diseases Society of America. Clin Infect Dis 1998;26:1042-59.

73. Mukhtar U, Shoukat U, Athar MK, Rincon F. Utility of biomarkers in the evaluation of fever in the intensive care unit after brain injury. JHN J 2017;12:6.

74. Fekety R. Guidelines for the diagnosis and management of Clostridium difficile-associated diarrhea and colitis. American College of Gastroenterology, Practice Parameters Committee. Am J Gastroenterol 1997;92:739-50.

75. DeMaio J, Bartlett JG. Update on diagnosis of Clostridium difficile-associated diarrhea. Curr Clin Top Infect Dis 1995; 15:97-114

76. Stein M, Caplan ES. Nosocomial sinusitis: a unique subset of sinusitis. Curr Opin Infect Dis 2005; 18:147-50.

77. Haley RW, Culver DH, White JW, Morgan WM, Emori TG, Munn VP, et al. The efficacy of infection surveillance and control programs in preventing nosocomial infections in US hospitals. Am J Epidemiol 1985;121:182-205.

78. Haley RW. Measuring the costs of nosocomial infections: methods for estimating economic burden on the hospital. Am J Med 1991;91(3B):32S-38S.

79. Johnson DH, Cunha BA. Drug fever. Infect Dis Clin North Am 
1996;10:85-91.

80. Busto R, Globus MY, Dietrich WD, Martinez E, Valdés I, Ginsberg MD. Effect of mild hypothermia on ischemia-induced release of neurotransmitters and free fatty acids in rat brain. Stroke 1989;20:904-10.

81. Kil HY, Zhang J, Piantadosi CA. Brain temperature alters hydroxyl radical production during cerebral ischemia/reperfusion in rats. J Cereb Blood Flow Metab 1996;16:100-6.

82. Dietrich WD, Busto R, Halley M, Valdes I. The importance of brain temperature in alterations of the blood-brain barrier following cerebral ischemia. J Neuropathol Exp Neurol 1990; 49:486-97.

83. Circiumaru B, Baldock G, Cohen J. A prospective study of fever in the intensive care unit. Intensive Care Med 1999;25:668-73.

84. Peres Bota D, Lopes Ferreira F, Mélot C, Vincent JL. Body temperature alterations in the critically ill. Intensive Care Med 2004;30:811-6.

85. Schulman CI, Namias N, Doherty J, Manning RJ, Li P, Elhaddad A, et al. The effect of antipyretic therapy upon outcomes in critically ill patients: a randomized, prospective study. Surg Infect (Larchmt) 2005;6:369-75.

86. Holtzclaw BJ. The febrile response in critical care: state of the science. Heart Lung 1992;21:482-501.

87. Busto R, Dietrich WD, Globus MY, Valdés I, Scheinberg P, Ginsberg MD. Small differences in intraischemic brain temperature critically determine the extent of ischemic neuronal injury.J Cereb Blood Flow Metab 1987;7:729-38.

88. Wass CT, Lanier WL, Hofer RE, Scheithauer BW, Andrews AG. Temperature changes of $>$ or $=1$ degree $\mathrm{C}$ alter functional neurologic outcome and histopathology in a canine model of complete cerebral ischemia. Anesthesiology 1995;83:32535 .

89. Dietrich WD, Alonso O, Halley M, Busto R. Delayed posttraumatic brain hyperthermia worsens outcome after fluid percussion brain injury: a light and electron microscopic study in rats. Neurosurgery 1996;38:533-41.

90. Minamisawa H, Smith ML, Siesjö BK. The effect of mild hyperthermia and hypothermia on brain damage following 5,10 , and 15 minutes of forebrain ischemia. Ann Neurol 1990; 28:26-33.

91. Jaber S, Chanques G, Altairac C, Sebbane M, Vergne C, Perrigault PF, et al. A prospective study of agitation in a medical-surgical ICU: incidence, risk factors, and outcomes. Chest 2005;128:2749-57.

92. Kiekkas P, Samios A, Skartsani C, Tsotas D, Baltopoulos GI. Fever and agitation in elderly ICU patients: a descriptive study. Intensive Crit Care Nurs 2010;26:169-74.
93. Aldemir M, Ozen S, Kara IH, Sir A, Baç B. Predisposing factors for delirium in the surgical intensive care unit. Crit Care 2001; 5:265-70.

94. Huschak G, Hoell T, Wiegel M, Hohaus C, Stuttmann R, Meisel HJ, et al. Does brain temperature correlate with intracranial pressure? J Neurosurg Anesthesiol 2008;20:105-9.

95. Bruder N, Raynal M, Pellissier D, Courtinat C, François G. Influence of body temperature, with or without sedation, on energy expenditure in severe head-injured patients. Crit Care Med 1998;26:568-72.

96. Hasday JD, Garrison A. Antipyretic therapy in patients with sepsis. Clin Infect Dis 2000;31 Suppl 5:S234-41.

97. Barie PS, Hydo LJ, Eachempati SR. Causes and consequences of fever complicating critical surgical illness. Surg Infect (Larchmt) 2004;5:145-59.

98. Mackowiak PA, Boulant JA. Fever's glass ceiling. Clin Infect Dis 1996;22:525-36.

99. Todd MM, Hindman BJ, Clarke WR, Torner JC, Weeks JB, Bayman EO, et al. Perioperative fever and outcome in surgical patients with aneurysmal subarachnoid hemorrhage. Neurosurgery 2009;64:897-908.

100. Rousseaux P, Scherpereel B, Bernard MH, Graftieaux JP, Guyot JF. Fever and cerebral vasospasm in ruptured intracranial aneurysms. Surg Neurol 1980;14:459-65.

101. Wartenberg KE, Schmidt JM, Claassen J, Temes RE, Frontera JA, Ostapkovich N, et al. Impact of medical complications on outcome after subarachnoid hemorrhage. Crit Care Med 2006;34:617-24.

102. Naidech AM, Bendok BR, Bernstein RA, Alberts MJ, Batjer $\mathrm{HH}$, Watts CM, et al. Fever burden and functional recovery after subarachnoid hemorrhage. Neurosurgery 2008;63:212-8.

103. Saxena M, Young P, Pilcher D, Bailey M, Harrison D, Bellomo $\mathrm{R}$, et al. Early temperature and mortality in critically ill patients with acute neurological diseases: trauma and stroke differ from infection. Intensive Care Med 2015;41:823-32.

104. Lausberg G. Significance of thermoregulatory disorders in the multi-injured with predominantly cranial lesion. Cah Anesthesiol 1971;19:315-24.

105. Ferguson A. Evaluation and treatment of fever in intensive care unit patients. Crit Care Nurs Q2007;30:347-63.

106. Henker R, Rogers S, Kramer DJ, Kelso L, Kerr M, Sereika S. Comparison of fever treatments in the critically ill: a pilot study. Am J Crit Care 2001;10:276-80.

107. Steele RW, Tanaka PT, Lara RP, Bass JW. Evaluation of sponging and of oral antipyretic therapy to reduce fever. J Pediatr 1970;77:824-9.

108. Lenhardt R, Negishi C, Sessler DI, Vuong K, Bastanmehr H, 
Kim JS, et al. The effects of physical treatment on induced fever in humans. Am J Med 1999;106:550-5.

109. O’Donnell J, Axelrod P, Fisher C, Lorber B. Use and effectiveness of hypothermia blankets for febrile patients in the intensive care unit. Clin Infect Dis 1997;24:1208-13.

110. Mayer S, Commichau C, Scarmeas N, Presciutti M, Bates J, Copeland D. Clinical trial of an air-circulating cooling blanket for fever control in critically ill neurologic patients. Neurology 2001;56:292-8.

111. Diringer MN; Neurocritical Care Fever Reduction Trial Group. Treatment of fever in the neurologic intensive care unit with a catheter-based heat exchange system. Crit Care Med 2004;32:559-64.

112. Schmutzhard E, Engelhardt K, Beer R, Brössner G, Pfausler B, Spiss $\mathrm{H}$, et al. Safety and efficacy of a novel intravascular cooling device to control body temperature in neurologic intensive care patients: a prospective pilot study. Crit Care Med 2002; 30:2481-8.

113. Keller E, Imhof HG, Gasser S, Terzic A, Yonekawa Y. Endovascular cooling with heat exchange catheters: a new method to induce and maintain hypothermia. Intensive Care Med 2003;29:939-43.

114. Hachimi-Idrissi S, Corne L, Ebinger G, Michotte Y, Huyghens L. Mild hypothermia induced by a helmet device: a clinical feasibility study. Resuscitation 2001;51:275-81.

115. Wang H, Olivero W, Lanzino G, Elkins W, Rose J, Honings D, et al. Rapid and selective cerebral hypothermia achieved using a cooling helmet. J Neurosurg 2004;100:272-7.
116. Liu WG, Qiu WS, Zhang Y, Wang WM, Lu F, Yang XF. Effects of selective brain cooling in patients with severe traumatic brain injury: a preliminary study. J Int Med Res 2006;34:58-64.

117. Toulmond S, Rothwell NJ. Interleukin-1 receptor antagonist inhibits neuronal damage caused by fluid percussion injury in the rat. Brain Res 1995;671:261-6.

118. Ginsberg MD, Busto R. Combating hyperthermia in acute stroke: a significant clinical concern. Stroke 1998;29:529-34.

119. Mendieta Zerón H, Arriaga García Rendon JC. Remission of central fever with morphine post traumatic brain injury. J Med Liban 2014;62:57-61.

120. Shemano I, Nickerson M. Effect of ambient temperature on thermal responses to drugs. Can J Biochem Physiol 1958;36: 1243-9.

121. Korepu P, Sriganesh K, Vinay B. Hyperpyrexia following hemispherotomy and role of unconventional therapy. J Neuroanaesth Crit Care 2014;1:210-1.

122. Natteru P, George P, Bell R, Nattanmai P, Newey CR. Central hyperthermia treated with bromocriptine. Case Rep Neurol Med 2017;2017:1712083.

123. Frenette AJ, Kanji S, Rees L, Williamson DR, Perreault MM, Turgeon AF, et al. Efficacy and safety of dopamine agonists in traumatic brain injury: a systematic review of randomized controlled trials. J Neurotrauma 2012;29:1-18.

124. Ünver Tuhan H, Anık A, Çatlı G, Abacı A, Öztürk T, Güleryüz $\mathrm{H}$, et al. Recovery of central fever after gh therapy in a patient with GH deficiency secondary to posttraumatic brain injury. J Clin Res Pediatr Endocrinol 2015;7:77-9. 